\title{
Karakteristik Negara Indonesia
}

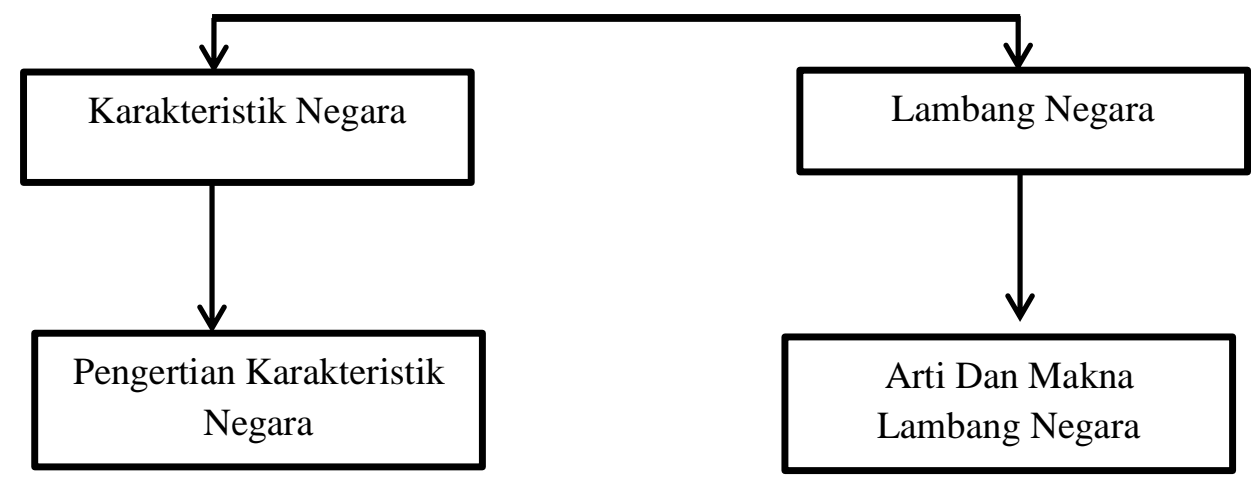




\section{BAB I}

\section{PENDAHULUAN}

\section{A. Latar Belakang}

Karakter sangat penting dalam membangun dalam membangun sebuah peradaban bangsa yang kuat dan berahlak mulia. Tanpa karakter sebuah bangsa yang dibagun atas seseorang dengan mudah melakukan sesuatu apapun yang dapat menyakiti atau menyengsarakan orang lain bahkan bangsa lain. Oleh karena itu perlu mengolah karakter untuk mengelola dari hal-hal negative. Karakter yang terbangun dan dapat dikembangkan diharapkan mampu mendorong setiap manusia dalam suatu bangsa untuk mengerjakan sesuatu sesuai dengan hati nurani dan dan peraturan yang ada. Pengembangan karakter pada domensi individual suatu bangsa berkaitan erat dengan kebiasaan yang dilakukan oleh seseorang pada tataran kebiasaan menanamkan nilai-nilai moral.

Sekolah dipandang sebagai tempat yang strategis untuk membentuk dan mengembangkan karakter. Hal ini dimaksudkan agar warga sekolah atau pelajar dalam ucapan, sikap, dan tindakan dapat mencerminkan karakter yang baik dan kuat. Penanaman dan pengembangan karakter di sekolah diarahkan pada terciptannya suasana yang kondusif agar memungkinkan semua unsur di sekolah dapat secara langsung maupun tidak langsung berpartisipasi secara aktif sesuai dengan peran dan fungsinya.

Guru sebagai contoh juga merupakan teladan bagi para peserta didiknya. Keteladanan adalah salah satu faktor penting seorang guru sebagai pendidik. Keteledanan dalam aspek bersifat multidimendi.

Karakter merupakan hal yang sangat esensial dalam berbangsa dan bernegara, oleh sebab itu hilangnya karakter akan akan menyebabkan hilangnya generasi bangsa. Karakter juga memiliki fungsi sebagai penggerak dan kekuatan sehingga bangsa ini tidak datang dengan 
sendirinya, namun harus dibangun dan dibentuk untuk menjadikan suatu bangsa bermartabat .

B. Rumusan Masalah

1. Apa itu Karakteristik Negara Indonesia .?

2. Apa itu Pembentukan Karakter.?

3. Bagaimana Rumusan Masalah Karakteristik Negara,?

C. Tujuan

1. Untuk Mengetahui Karakteristik Negara

2. Untuk Mengetahui Pentingnya Karakter untuk Pendidikan

3. Untuk Mengetahui Rumusan karakterisik Negara 


\section{BAB II}

\section{PEMBAHASAN}

\section{A. Karakteristik Negara Indonesia}

Setelah Indonesia lahir maka dibentuk dan disepakati terkait karakteristik Negara Indonesia yang didalam nya berisikan identitas nasional Indonesia. Setiap Negara memiliki suatu identitas untuk melambangkan keagugan suatu Negara. Setiap Negara Indonesia yang memiliki identitas yamg dapat menjadi penciri atau pembangun jati diri bangsa Indonesia. Identitas Indonesia menjadi kan bangsa Indonesia sebagai persatu dan simbol kehormatan Negara. Selain itu identitas nasional menjadikan Negara Indonesia yang bermartabat diantara Negara-negara yang lain yang memiliki beragam kebudayaan, agama, dan memiliki jiwa toleransi maupun soledaritas yang tinggi.

\section{Bendera Negara Sang Merah Putih}

Ketentuan tentang bendera Negara diatur dalam Undang-undang Negara No. 24 Tahun 2009 mulai Pasal 4 sampai Pasal 24. Bendera merah putih dikibarkan pertama kali pada Tanggal 17 Agustus 1945 pada saat sumpah pemuda tahun 1928. Bendera Sang Merah Putih dikibarkan saat Proklamasi Kemerdekaan Bangsa Indonesia pada tanggal 17 Agustus 1945 di jalan Pegangsaan Timur Nomor 56 Jakarta disebut Bendera Pusaka Sang Saka Merah Putih. ${ }^{1}$ Bendera Pusaka Sang Saka Merah Putih disimpan dan dipelihara di monument Nasional Jakarta

2. Bahasa Negara Indoeisa

Ketentuan Bahasa Negara diatur dalam Undang-undang No. 24 Tahun 2009 mulai Pasal 25 sampai 45. Bahasa Indonesia sebagai bahasa Negara merupakan hasil kesepakatan para pendiri Negara

${ }^{1}$ Maulana Arafat Lubis, Pembelajaran Ppkn di SD/MI Kelas Rendah, (Bandung: Manggu Makmur Tanjung Lestari, 2019),hlm.,43. 
Kesatuan Republik Indonesia (NKRI). Bahasa Indonesia berasal dari rumpun bahasa Melayu yang dipergunakan sebagai bahasa pergaulan (lingua franca), setelah itu diangkat dan diikrarkan sebagai bahasa persatuan pada kongres Pemuda II tanggal 28 Oktober 1928. Bangsa Indonesia sepakat bahwa bahasa Indonesia merupakan bahasa nasional sekaligus sebagai jati diri dan identitas nasional Indonesia.

3. Lambang Negara Garuda Pancasila dan Simbol-simbol Pancasila

a. Lambang Negara Garuda Pancasila

Pada tanggal 13 Juli 1945, dalam rapat panitia perancangan Undang-undang Dasar 1945. Salah seorang anggota penitia bernama Parada Harahap mengusulkan tentang lambang Negara. Tanggal 16 November 1945 baru dibentuk panitia Indonesia Raya. Panitia ini bertugas menyelidiki arti lambang-lambang dalam peradaban bangsa Indonesia sebagai langkah awal untuk mempersiapkan bahan kajian tenteng Negara. Panitia Indonesia Raya diketahui oleh Ki Hajar Dewantara dengan sekretaris Muhammad Yamin.

Adapun ciri-ciri lambang Negara Garuda Pancasila adalah:

I. Warna dan Jumlah Helai Bulu

1) Warna

a) Seluruh Burung Garuda, Bintang, Kapas, Padi dan Rantai - Kuning Emas.

b) Ruangan perisai diengah-tengah Merah Putih

- Kiri atas dan kanan bawah - Merah

c) Kanan atas dan kiri bawah - Putih

d) Dasar Bintang yang berbentuk perisai Hitam

e) Kepala Banteng - Hitam

f) Pohon Beringin - Hijau 
g) Pita - Putih

h) Huruf - Hitam

2) Jumlah Helai Bulu
a) Pada tiap sayap - 17 helai
b) Pada ekor -8 helai
c) Kecil di bawah perisai - 10 helai
d) Kecil di leher -45 helai

\section{Arti dan Makna Lambang Negara}

Adapun arti dan makna simbolik dari lambang Negara ialah Garuda ialah burung yang dinamakan juga "Sang Raja Wali", seperti yang disebutkan dalam cerita Ramayana dan Bharatayuda.

1) Burung tersebut merupakan lambang kekuasaan dan kekuatan

2) Sayap yang masing-masing terdiri dari 17 helai, berarti tanggal 17. Ekor berung yang terdiri dari 8 helai, berarti bulan ke-8 atau bulan Agustus.

3) Jumlah bulu kecil di bawah perisai sebanyak 19 helai dan jumlah bulu kecil dibawah leher sebanyak 45 helai, berarti tahun 1945

Hal ini mengigetkan kita pada tanggal 17 Agustus 1945, Hari Proklamasi Kemerdekaan Negara Kesatuan Republik Indonesia, yang dikumandangkan oleh Dwi-Tunggal Soekarno-Hatta di Jalan Pegangsaan Timur (sekarang Jalan Proklamasi) nomor 56 Jakarta.

a. Perisai

1. Perisai atau temeng yang berbentuk jantung yang leher Burung Garadu adalah lambang perlindungan. 
2. Garis melintang di tengah-tengah perisai melukiskan khalustiwa (equator). Hal ini menunjukkan bahwa kepulauan Indonesia laksana ratna mutu menikam bertaburan di sekitar khatulistiwa.

b. Ruangan pada Perisai

Lima buah ruangan pada perisai memuat symbolsimbol dasar Negara kesatuan Republik Indonesia, yaitu:

1. Nur-cahaya berbentuk bintang bersudut lima, melambangkan dasar ketuhanan yang Maha Esa (theokrasi). $^{2}$

2. Rantai bermata bulat (lambang pria) dan persegi (lambang wanita) saling berkaitan mata rantai persatuan, melambangkan Dasar kemerdekaan yang adil dan beradab atau peri-kemanusiaan (Humanisme).

3. Pohon beringin melambangkan persatuan Indonesia atau Kebangsaan (Nasionalisme).

4. Kepala benteng adalah lambang tenaga rakyat dan menunjukkan Dasar Kerakyatan yang Dipimpin oleh Hikmah Kebijaksanaan dalam Permusyawaratan/Perwakilan (Demokrasi Pancasila)

5. Kapas dan padi ( sedang pangan) melambangkan tujuan kemakmuran bersama, yakni keadilan Sosial bagi Seluruh Rakyat Indonesia (Sosialisme).

\footnotetext{
${ }^{2}$ Maulana Arafat Lubis, Pembelajaran Ppkn di SD/MI Kelas Rendah, (Bandung: Manggu Makmur Tanjung Lestari, 2019),hlm.,48
} 
1. Karakteristik Negara Kesatuan
a. Bersifat suka rela
b. Bersatu dalam perbedaan
c. Minat mutual
d. Rasa memiliki dan kebanggan
e. Saling pecaya diri
f. Persaingan positif
g. Melestarikan Minat Regional dan Interanasional

2. Negara Kesatuan dan persatuan Nasional

Jika persatuan nasional tidak ada, karena alasan apapun, maka komplik adalah hasil yang mungkin digunakan untuk menunjukkan penyatuan berbagai kelompok orang yang disatukan oleh karakteristik khusus di wilayah geografis dan memiliki otoritas politik. ${ }^{3}$

${ }^{3}$ Muslich "Karekteristik Negara Indonesia", Jurnal pembangun, Vol. 2, No. 3 JuliSeptember 2007, hal. 4, http://jhp.ui.ac.id/index.php/home/article/download/151/89 diakses 18 September 2019, Pukul 09:49 


\section{BAB III}

\section{PENUTUP}

A. Kesimpulan

Karakteristik ialah ciri khas yang melekat pada pribadi seseorang atau sekolompok orang yang tercermin dalam suatu perbuatan/perilaku yang mengandung nilai-nilai tertentu.

Karakter menurut Hidayatullah (2010:16), karakter adalah kualitas atau kekuatan mental atau moral, ahlak atau budi pekerti individu yang merupakan kepribadian khusus yang menjadi pendorong dan pengerak, serta yang membedakan dengan individu yang lain.

Karakteristik sangat penting dalam membangun sebuah peradaban bangsa yang kuat dan berakhlak mulia. Tanpa karakter sebuah bangsa yang dibangun atas seseorang dengan mudah melakukan sesuatu apapum yang dapat menyakiti atau menyengsarakan orang lain bahkan bangsa lain. Oleh karena itu perlu mengolah karakter untuk mengelola dari hal-hal negative. Karakter yang terbagun dan dapat dikembangkan diharapkan mampu mendorong setiap manusia dalam suatu bangsa untuk mengerjakan sesuatu sesuai dengan hati nurani dan peraturan yang $\operatorname{ada}^{4}$.

B. Saran

Manusia tidak luput dari kesalahan, adan apabila ada kesalahan penulisan maupun penyusunan dalam makalah ini kami mohon keritik dan saran para pembaca. Terimah kasih atas partisipasinya dan mohon maaf atas kesalahan dalam penulisan makalah ini, karena kesempurnaan hanyalah milik Allah SWT.

\footnotetext{
${ }^{4}$ Didin Budiman "psikologi anak dalam karakteristik siswa Sekolah Dasar" diakses tanggal 18 September 2019, Pukul 09:45 http://file.upi.edu/Direktor/FPOK/JURNAL
} 


\section{DAFTAR PUSTAKA}

Arafat Maulana Lubis, Pembelajaran Ppkn di SD/MI Kelas Rendah, Bandung: Minggu Makmur Tanjung Lestari, 2019. Arafat Maulana Lubis, Pembelajaran Ppkn di SD/MI Kelas Rendah, Bandung: Minggu Makmur Tanjung Lestari, 2019. Budiman Didin "psikologi anak dalam karakteristik siswa Sekolah Dasar" http://file.upi.edu/Direktor/FPOK/JURNAL.

Muslich "Karekteristik Negara Indonesia”, Jurnal pembangun, Vol. 2, No. 3 Juli-September 2007, http://jhp.ui.ac.id/index.php/home/article/download/151/89 